\title{
X-ray patterns of COVID-19 in patients presenting to Lady Reading Hospital, Peshawar, Pakistan
}

\author{
Tahira Nishtar ${ }^{1}$, Nosheen Noor ${ }^{2}$, \\ Shandana Latif Khan ${ }^{3}$
}

\begin{abstract}
Objective: To determine the pattern of COVID-19 on chest radiograph in patients presenting to Lady Reading Hospital, Peshawar, Pakistan.

Methods: This prospective observational study was conducted on 178 consecutive swab positive COVID-19 patients presenting to Lady Reading Hospital, Peshawar, Pakistan from $15^{\text {th }}$ March to $15^{\text {th }}$ June 2020. Patients of all ages and both genders were included. Chest X-rays performed by portable radiography unit were viewed for different patterns by two consultant radiologists independently and results were analyzed using IBM SPSS 20.

Results: Out of 178 patients 134 were male. Mean age was 55.67 years. Radiographic patterns observed were ground glass haze without or with reticulation and/or consolidation ( $45.5 \%$ and $33.2 \%$ respectively) and predominant consolidation either alone or in combination with ground glass haze or other findings ( $27.1 \%$ collectively). Peripheral distribution pattern was seen in $69.1 \%$ of patients with bilateral findings in $84.3 \%$. Further categorization was based on pulmonary zonal demarcation with changes most commonly involving four zones (33.1\%) i.e., the lower and mid zones bilaterally.

Conclusion: Portable chest radiography is an essential supporting tool for assessing different patterns in COVID-19 infection. The most common pattern observed is alveolar opacities with predominant peripheral distribution either unilateral or more frequently bilateral, starting from the lower and mid zones extending to the upper zones and becoming diffuse with disease progression.
\end{abstract}

KEYWORDS: COVID-19, Portable X-ray, Chest X-ray findings.

How to cite this:

doi: https://doi.org/10.12669/pjms.37.1.3435

Nishtar T, Noor N, Khan SL. X-ray patterns of COVID -19 in patients presenting to Lady Reading Hospital, Peshawar, Pakistan. Pak J Med Sci. 2021;37(1):28-33. doi: https://doi.org/10.12669/pjms.37.1.3435

This is an Open Access article distributed under the terms of the Creative Commons Attribution License (http://creativecommons.org/licenses/by/3.0), which permits unrestricted use, distribution, and reproduction in any medium, provided the original work is properly cited.

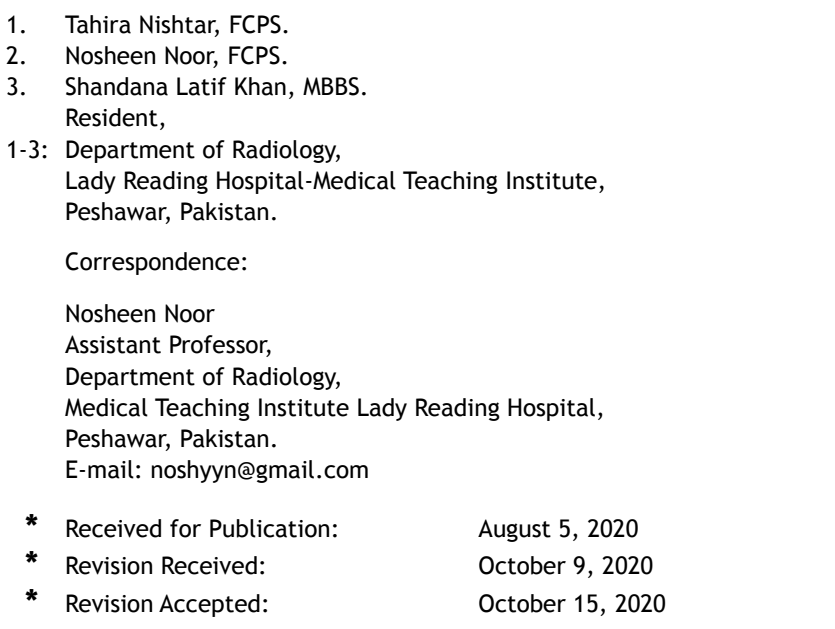

Pak J Med Sci January - February $2021 \quad$ Vol. $37 \quad$ No. $1 \quad$ www.pjms.org.pk 28

\section{INTRODUCTION}

COVID-19, caused by SARS-COV-2, declared a pandemic by world health organization (WHO) in March 2020, has had a global impact since it first emerged in WUHAN, CHINA in late December 2019. ${ }^{1}$ In Pakistan the first case was reported on $26^{\text {th }}$ February 2020 in Karachi. ${ }^{2}$ As of July 2, 2020, about 10,533,779 confirmed cases of COVID-19 have been reported worldwide, resulting in 512,842 deaths in 216 countries. ${ }^{3}$ In Pakistan, 217,809 cases of COVID-19 have been confirmed and 4,473 deaths till date with increasing daily numbers of people testing positive for Corona virus. ${ }^{4}$ 
Chest radiograph though less sensitive than CT chest, is the first line imaging modality used for COVID-19 patients, with portable chest radiography units used for ease of decontamination and eliminating the need of patient transfer. ${ }^{5-9}$ Most of radiological literature focuses on chest CT role and manifestations in COVID -19. According to some studies performed in China, CT has achieved a diagnostic sensitivity even higher than initial RT-PCR swab test ${ }^{10}$ but due to infection control issues, decontamination and lack of CT availability in certain parts of the world, portable chest radiography is the most frequently used imaging modality for identification and follow up of lung manifestations of COVID-19. The American College of Radiology notes that CT decontamination required after scanning COVID-19 patients could disrupt radiological services and portable radiography may be considered to reduce risk of cross contamination. ${ }^{11}$

The rationale of the study was to highlight the different radiographic patterns of COVID-19 which is an essential parameter in both disease diagnosis and prognosis.

\section{METHODS}

This prospective observational study were conducted on an initial series of consecutive 178 patients presenting with COVID-19 infection to Lady Reading Hospital (LRH), Peshawar, Pakistan from $15^{\text {th }}$ March to $15^{\text {th }}$ June 2020. The

Table-I: Patient demographics \& clinical features.

\begin{tabular}{lcc}
\hline Variable & $\begin{array}{c}N= \\
178\end{array}$ & $\begin{array}{c}\text { Percentage } \\
(\%)\end{array}$ \\
\hline Age (years): & & \\
$\quad$ Range & $12-90$ & \\
$\quad$ Mean & 55.67 & \\
Gender: & & \\
Males & 134 & 75.3 \\
Females & 44 & 24.7 \\
Presenting symptoms: & & \\
Fever, cough \& SOB & 158 & 88.8 \\
Cough \& SOB & 12 & 6.7 \\
Cough & 2 & 1.1 \\
SOB & 2 & 1.1 \\
Cough \& fever & 1 & 0.6 \\
Cough, SOB \& diarrhea & 1 & 0.6 \\
Diarrhea & 1 & 0.6 \\
Fever, cough, SOB \& irritability & 1 & 0.6 \\
\hline
\end{tabular}

$\mathrm{SOB}=$ shortness of breath. research protocol was approved by institutions ethics committee on $18^{\text {th }}$ June 20202 under reference number 484/LRH. Patients of all ages and both genders admitted in isolation ward, high dependency units (HDU) and intensive care units (ICU) were included in the study. Portable chest radiography was performed and viewed for radiographic patterns. A proforma was devised including patient's demographics, presenting symptoms, co-morbidities and $\mathrm{X}$ - ray findings. Each chest X- ray was viewed by two consultant radiologists independently. Results were analyzed using IBM SPSS 20 version.

\section{RESULTS}

Total number of patients included in the study are 178. Male to female ratio was almost 3:1 with mean age of 55.6 years. Commonest clinical presentation noted was fever, cough and shortness of breath in $88.2 \%$ of patients (Table-I). In $57.9 \%$

Table-II: Comorbidities.

\begin{tabular}{|c|c|c|}
\hline Comorbidity & $\begin{array}{c}\text { Fre- } \\
\text { quency }\end{array}$ & $\begin{array}{c}\text { Per- } \\
\text { centage }\end{array}$ \\
\hline None & 103 & 57.9 \\
\hline $\mathrm{DM}$ & 20 & 11.2 \\
\hline DM \& HTN & 14 & 7.9 \\
\hline HTN & 7 & 3.9 \\
\hline Hepatitis C & 5 & 2.8 \\
\hline HTN \& IHD & 4 & 2.2 \\
\hline Obesity & 3 & 1.7 \\
\hline Asthma & 2 & 1.1 \\
\hline COPD & 2 & 1.1 \\
\hline DM \& hepatitis C & 2 & 1.1 \\
\hline DM, HTN \& asthma & 2 & 1.1 \\
\hline DM, HTN \& CKD & 2 & 1.1 \\
\hline DM \& obesity & 2 & 1.1 \\
\hline HTN \& stroke & 2 & 1.1 \\
\hline DM \& asthma & 1 & 0.6 \\
\hline DM, HTN \& epilepsy & 1 & 0.6 \\
\hline DM, HTN, hepatitis C \& anemia & 1 & 0.6 \\
\hline HTN \& hepatitis C & 1 & 0.6 \\
\hline Ischemic heart disease & 1 & 0.6 \\
\hline IHD, DM \& HTN & 1 & 0.6 \\
\hline IHD, HTN \& obesity & 1 & 0.6 \\
\hline Hepatitis B & 1 & 0.6 \\
\hline Total & 178 & 100.0 \\
\hline \multicolumn{3}{|c|}{$\begin{array}{l}\text { DM = diabetes mellitus, HTN= Hypertension, } \\
\text { IHD = ischemic heart disease, } \\
\text { COPD = chronic obstructive pulmonary disease, } \\
\text { CKD = chronic kidney disease. }\end{array}$} \\
\hline
\end{tabular}

$\begin{array}{lllll}\text { Pak J Med Sci January - February } 2021 & \text { Vol. } 37 & \text { No. } 1 \quad \text { www.pjms.org.pk } 29\end{array}$ 
of patients there is no associated co morbidity. In the remaining, diabetes mellitus and hypertension were the commonest comorbidities (25.9 and $20.3 \%$ respectively) (Table-II).

X-Ray patterns seen frequently were ground glass haze without or with reticulation and/or consolidation (45.5\% and $33.2 \%$ respectively) and predominant consolidation either alone or in combination with ground glass haze and reticulation or other rare findings (27.1\% collectively). (Table-III)

Table-III: X-Ray findings.

\begin{tabular}{|c|c|c|}
\hline Variable & $\begin{array}{l}N= \\
178\end{array}$ & $\begin{array}{c}\text { Perce- } \\
\text { ntage } \\
(\%)\end{array}$ \\
\hline Normal X-Ray & 5 & 2.8 \\
\hline \multicolumn{3}{|l|}{ Pattern: } \\
\hline GGH & 81 & 45.5 \\
\hline GGH \& reticulation & 39 & 21.9 \\
\hline Consolidation & 19 & 10.7 \\
\hline GGH \& consolidation & 18 & 10.1 \\
\hline GGH, consolidation \& reticulation & 7 & 3.9 \\
\hline Reticulation & 3 & 1.7 \\
\hline Consolidation \& soft nodules & 1 & 0.6 \\
\hline Consolidation, nodules \& reticulation & 1 & 0.6 \\
\hline Consolidation \& reticulation & 1 & 0.6 \\
\hline GGH, consolidation \& pleural effusion & 1 & 0.6 \\
\hline GGH, nodules \& reticulation & 1 & 0.6 \\
\hline Soft nodules & 1 & 0.6 \\
\hline \multicolumn{3}{|l|}{ Distribution: } \\
\hline Peripheral & 123 & 69.1 \\
\hline Diffuse & 49 & 27.5 \\
\hline Central & 1 & 0.6 \\
\hline \multicolumn{3}{|l|}{ Laterality: } \\
\hline Bilateral & 150 & 84.3 \\
\hline Right side & 13 & 7.3 \\
\hline Left side & 10 & 5.6 \\
\hline \multicolumn{3}{|l|}{ Zone: } \\
\hline Middle \& lower & 105 & 59 \\
\hline Upper, middle \& lower & 59 & 33.1 \\
\hline Lower & 7 & 3.9 \\
\hline Middle & 2 & 1.1 \\
\hline \multicolumn{3}{|l|}{ Number of zones/scores: } \\
\hline Four zones & 59 & 33.1 \\
\hline Three zones & 32 & 18.0 \\
\hline Five zones & 30 & 16.9 \\
\hline Six zones & 26 & 14.6 \\
\hline Two zones & 24 & 13.5 \\
\hline One zone & 2 & 1.1 \\
\hline
\end{tabular}

$\mathrm{GGH}=$ ground glass haze .
Peripheral distribution was seen in $69.1 \%$ of patients with diffuse pattern in $27.5 \%$. Bilateral changes seen in $84.3 \%$ of patients, unilateral changes in $12.9 \%$ with right sided predominance. Middle and lower zone involvement was commonest i.e. 59\%, all three zones (upper, middle and lower) were involved in $33.1 \%$, isolated lower and middle zone involvement was seen in $3.9 \%$ and $1.1 \%$ of patients respectively. As far as number of zones is concerned four zone involvement was seen in $33.1 \%$, three zones in $18 \%$, five zones in $16.9 \%$, six zones in $14.6 \%$, two zones in $13.5 \%$ and one zone in $1.1 \%$ of patients. Normal chest radiograph noted in $2.8 \%$ patients. (Table-III)

\section{DISCUSSION}

Imaging findings in COVID-19 are most commonly of atypical organizing pneumonia, often with bilateral, peripheral and basal predominant distribution. ${ }^{7}$ Different patterns observed in the study were ground glass haze in the early phase with increasing density as the disease progresses. Next stage is the development of heterogeneous dense lobar consolidation becoming homogenous and multi lobar as the disease progresses.

For ease of assessment of degree of lung involvement by disease process, its progression and resolution, a scoring system was devised based on zonal demarcation of lungs, with three zones on each side, i.e. the upper, the middle and the lower zones, each occupying about one third height of the lungs. Arbitrary demarcations of the zones are: from apices to the anterior border of second rib is the upper zone, the middle zone is up to the anterior border of the fourth rib and below that is the lower zone up to the level of diaphragms. The lung zones do not correspond to the lobes for example the lower zone on right includes middle and lower lobes. ${ }^{12}$ Hence, solitary zone involvement given a score of one with maximum score going up to 6 .

Most of the patients presenting to LRH were critically ill being admitted to the high dependency and intensive care units and mobile chest radiography was used for imaging. The national guidelines of radiological society of Pakistan (RSP) has also recommended the use of chest radiography for severe and critically ill patients. ${ }^{13}$ It is pertinent to note that majority of patients presenting to emergency department of LRH had a score of at least four, on the base line X-ray. Lady Reading Hospital being the largest 
tertiary care hospital in Khyber Pukhtunkhwa province of Pakistan, offers free of cost imaging services in both emergency department, inpatient and bed side portable X-ray services. All imaging and reports are available on picture archiving and communication system (PACS).

In the COVID 19 pandemic mobile X-ray unit is the preferred imaging modality used worldwide due to ease of decontamination and most suitable for critically ill patients on support. ${ }^{5-7}$ Serial X-rays were performed on patients who had longer duration of hospital stay. X-ray findings were evaluated in terms of the pattern, distribution, unilateral or bilateral disease and the number of zones involved.

X-ray findings may be normal in early disease and tend to appear about 10-12 days after onset of symptoms and normal CXR were seen in 31\% of patients in study performed by Wong et al. ${ }^{1,7}$ In our study, only $2.8 \%$ patients had normal X-ray at presentation. However, majority of the patients presented with advance disease and an abnormal X-ray on admission. The common findings in COVID-19 on CT include ground glass opacities with or without reticulation and consolidations mostly bilateral, peripheral and involving lower lung fields. ${ }^{5}$

Peripheral distribution is a common feature of COVID 19, on CT chest reported to be up to $86 \%$ by $\mathrm{Ng}$ et al. ${ }^{14}$ These peripheral opacities can be appreciated on CXR as well. ${ }^{1}$ Diffuse opacities

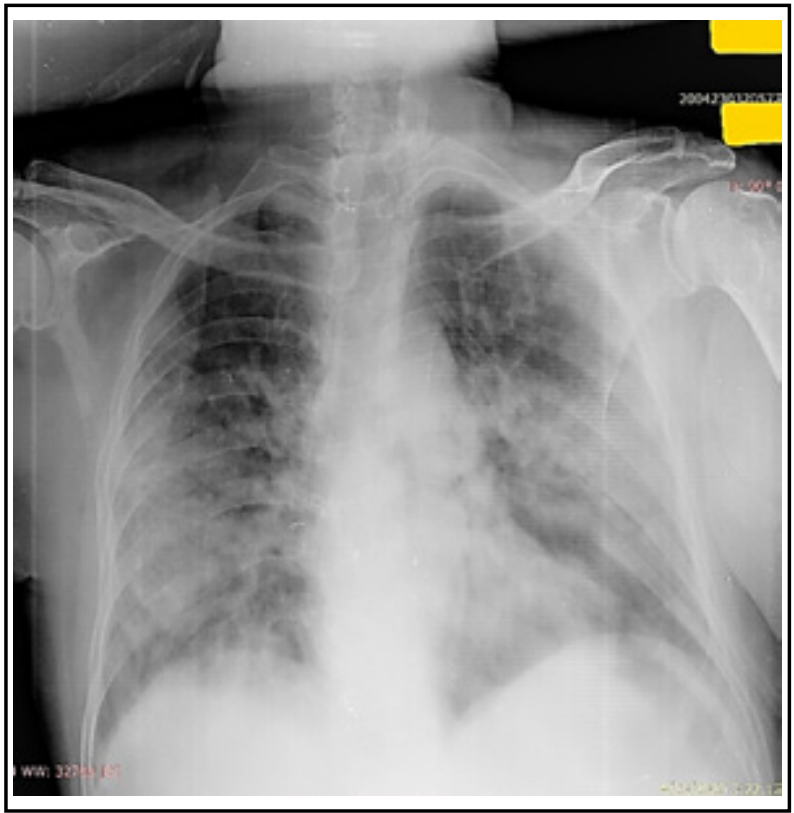

Fig.1: Predominant peripheral heterogeneous opacities involving bilateral middle and lower zones. can be seen in advanced disease. ${ }^{6}$ In our study peripheral distribution was the commonest in $69.1 \%$, with diffuse changes seen in $27.5 \%$ of patients. The commonest finding in our study was peripheral alveoar opacities, either in the form of ground glass haze or consolidation. Ground glass opacities according to the same author were seen in $86 \%$ and consolidation in $62 \%$ cases,$^{15}$ whereas, in our study ground glass haze either in isolation or in combination with other findings was seen in $78.7 \%$ of patients and consolidation in $27.1 \%$ of patients. (Table-III). Rare radiological findings of COVID-19 according to different studies include pleural effusion, cavitation, pneumothorax, solid nodules, pericardial effusion and mediastinal or hilar lymphadenopathy. ${ }^{5}$ Rare findings in our study were pulmonary nodules and pleural effusion. (Table-III)

In COVID-19 pneumonia findings are usually bilateral $67 \%,{ }^{6}$ however unilateral involvement is seen in equal number of patients according to some studies. ${ }^{1}$ In our study bilateral changes were noted in $84.3 \%$ of patients, with unilateral disease $(12.9 \%)$ presenting as right sided predominance (right side $7.3 \%$ and left side $5.6 \%$ ) (Fig.1 \& 2).

Mid and lower zones involvement is a common feature of the disease with upper zone involvement seen rarely. ${ }^{16}$ In our study mid and lower zones were involved in 59\%, upper zones extension of disease process seen in severe

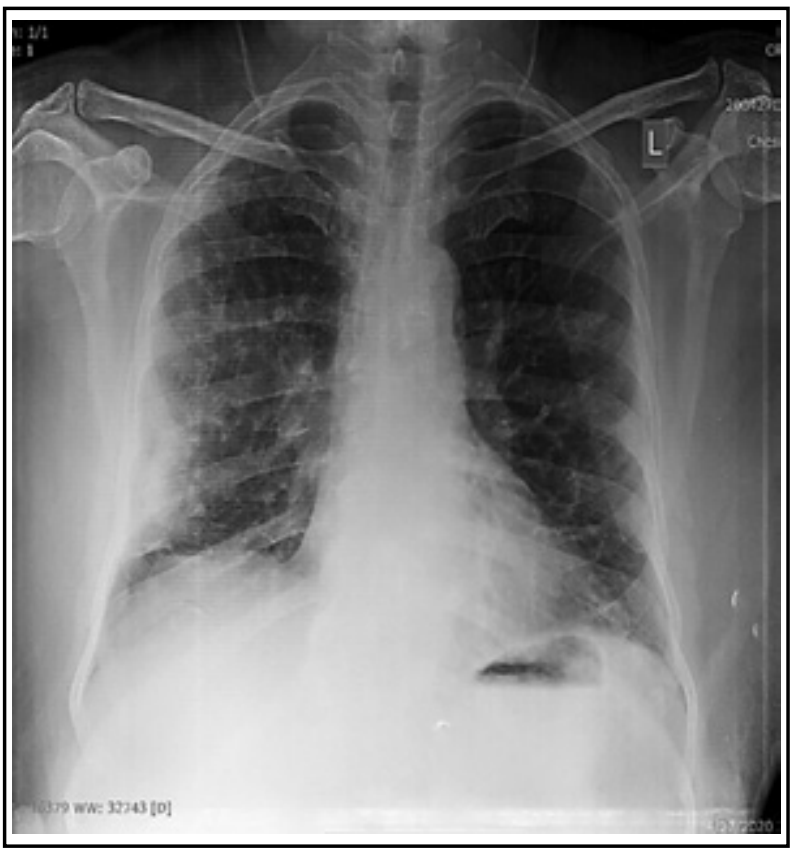

Fig.2: Right middle and lower zone peripheral opacity. 


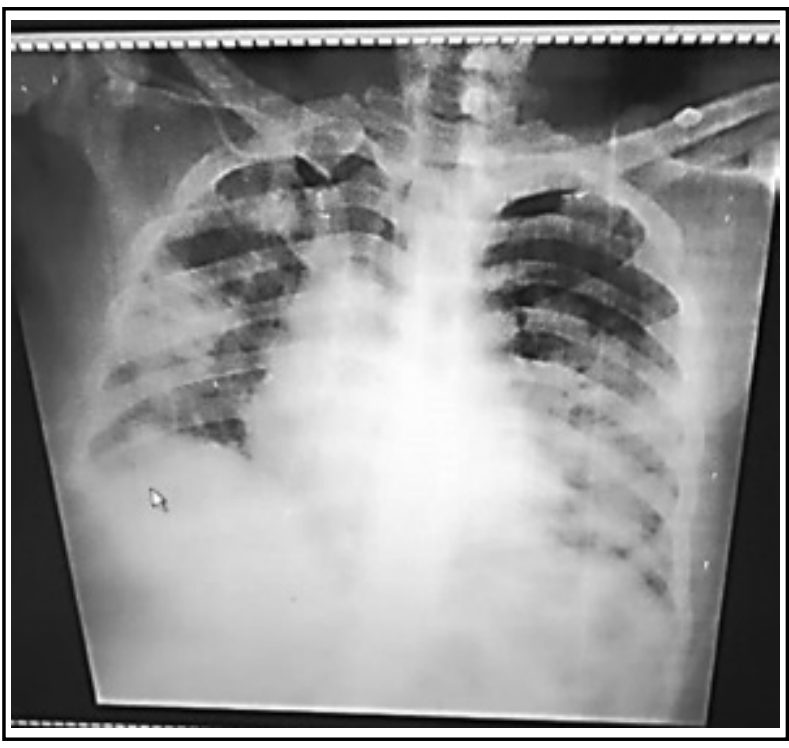

Fig.3 (a): 49 years old male patient chest X-ray on presentation showed right three zone and left two zone heterogeneous predominant peripheral opacities.

cases. Isolated upper zone involvement was not seen in any patient. Multiple zone involvement was common, with four zones predominant involvement (33.1\%) i.e., lower and middle zones bilaterally, with the left upper zone usually the last one to be involved (Table-III).

Note was made of an interesting phenomenon in few patients with serial X-rays where reversal of pattern was noted with resolution of consolidation from upper to the lower zones and from center to periphery, changing from dense consolidation to GGH with prominent bronchovascular marking and resolution of the opacities (Fig.3a \& b).

Mean age in our study was 55.6 years, compared to 56 years in study performed by Wong et al and 47 years by Guan et al. ${ }^{16,17}$ In our study the number of males affected was thrice as females, however, according to a study performed in China more women were affected than men. ${ }^{17}$ The difference in gender prevalence in our study is likely due to cultural factor, majority of Pakistani women being confined indoors and with full outer adornment including face shielding while in public, which plays a protective role in disease transmission. ${ }^{18}$

Common symptoms in study done in China were cough $(67.8 \%)$ and fever $(43.8 \%)$ with diarrhea uncommon (3.8\%). ${ }^{17}$ Our study also showed the commonest symptoms to be fever, cough and shortness of breath more than $90 \%$, while the uncommon symptoms were diarrhea (Table-I)

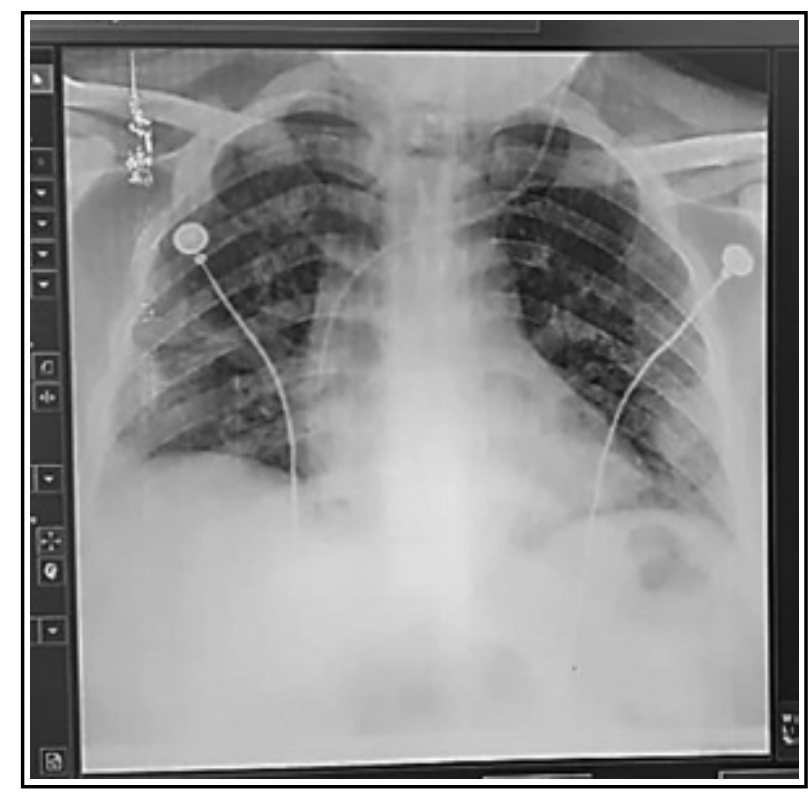

Fig.3 (b): Same patient as in Fig 3(a) chest X-ray at discharge showed significant resolution of the opacities.

According to Wong et al the frequent comorbidities were diabetes and hypertension, 13 and $20 \%$ respectively..$^{16}$ In our study diabetes mellitus and hypertension were the commonest co-morbidities (Table-II). An important finding to note in the study is that 103 out of 178 patients $(57 \%)$ at presentation did not have an associated co morbidity. In studies performed worldwide, most of the severely ill patients had one or more comorbidity. ${ }^{19}$

A study carried out in China showed that men had more severe disease with worse outcome compared to women, $70.3 \%$ mortality in men and $29.7 \%$ in women. ${ }^{20}$ In our study the mortality for women was slightly higher than in men, i.e. $68.2 \%$ for women and $61.2 \%$ for men.

\section{CONCLUSION}

Imaging is essential for assessing severity and disease progression in COVID-19 pneumonia. Radiologists and clinicians should be well versed with imaging manifestations of this infection. Chest $X$-ray is the first line imaging investigation with portable radiography being the most suitable imaging tool for critically ill patients in this highly contagious viral pandemic. The most important radiographic findings are peripheral alveolar opacities starting from the lower and mid zones extending to the upper zones and becoming diffuse with disease progression. 


\section{REFERENCES}

1. Adhikari SP, Meng S, Wu Y, Mao Y, Ye R, Wang Q, et al. Epidemiology, causes, clinical manifestation and diagnosis, prevention and control of coronavirus disease (COVID-19) during the early outbreak period: a scoping review. Infect Dis Poverty. 2020;29(9). doi: 10.1186/ s40249-020-00646-x

2. Waris A, Atta U, Ali M, Asmat A, Baset A. COVID-19 outbreak: current scenario of Pakistan. New microbe and new infect. 2020;35(C). doi: 10.1016/j.nmni.2020.100681

3. Rolling updates on coronavirus disease. Coronavirus disease (COVID-19) pandemic - WHO. June 2020. (https://www.who.int/emergencies/diseases/novelcoronavirus-2019)

4. Government of Pakistan Stats COVID-19. (http://covid. gov.pk)

5. Jacobi A, Chung M, Bernheim A, Eber C. Portable chest X-ray in coronavirus disease-19 (COVID-19): A pictorial review. Clin Imaging. 2020;64:35-42. doi: 10.1016/j. clinimag.2020.04.001

6. Durrani M, Inam-ul-Haq, Kalsoom U, Yousaf A. Chest X-rays findings in COVID 19 patients at a University Teaching Hospital - A descriptive study. Pak J Med Sci. 2020;36 (COVID 19-S4). doi: 10.12669/pjms.36. COVID19-S4.2778

7. Fatima S, Ratnani I, Husain M, Surani S. Radiological Findings in Patients with COVID-19. Cureus. 2020;12(4):e7651. doi: 10.7759/cureus.7651

8. Sohail, S. Rational and practical use of imaging in COVID-19 pneumonia. Pak J Med Sci. 2020;36(COVID19-S4). doi: 10.12669/pjms.36.COVID19-S4.2760

9. Shahzeb M, Khan A, Muhammad A. Role of imaging technology and current status of corona virus disease 2019 (covid-19): A critical review. Pak Heart J. 2020;53(01):5-9. doi: 10.47144 / phj.v53i1.1894

10. Czawlytko C, Hossain R, White CS. COVID-19 Diagnostic Imaging Recommendations. Applied Radiology. J Prac Imag Manag. 2020;49(3):10-15. https://appliedradiology. com/articles / covid-19-diagnostic-imagingrecommendations

11. American College of Radiology. ACR Recommendations for the use of Chest Radiography and Computed Tomography (CT) for Suspected COVID-19 Infection [Internet]. [US]; Mar 11, 2020; [updated Mar 22, 2020]. (https://www.acr.org/Advocacy-and-Economics/ ACR-Position-Statements/Recommendations-for-ChestRadiography-and-CT-for-Suspected-COVID19-Infection)

12. Chest X-Ray anatomy Lung zones. Radiology masterclass. www.radiologymasterclass.co.uk/tutorials/chest/chest home_anatomy/chest_anatomy_page3
13. Khan AN, Din NU, Umer US. COVID-19 National Pakistan Guidelines: Radiological Society of Pakistan (RSP) Recommendations Regarding Utilisation of Chest Imaging. May 2020; 70:5. doi: https://doi.org/10.5455/ JPMA.03

14. Ng M, Lee EYP, Yang J, Yang F, Li X, Wang $\mathrm{H}$, et al. Imaging Profile of the COVID-19 Infection: Radiologic Findings and Literature Review. Radiol Cardiothorac Imaging. 2020;2(1). doi: 10.1148/ryct.2020200034

15. Lomoro P, Verde F, Zerboni F, Simonetti I, Borghi C, Fachinetti C, et al. COVID-19 pneumonia manifestations at the admission on chest ultrasound, radiographs, and CT: single-center study and comprehensive radiologic literature review; Eur J Radiol Open. 2020;7:100231. doi: 10.1016/j.ejro.2020.100231

16. Wong HYF, Lam HYS, Fong AH, Leung ST, Chin TW, Lo CSY, et al. Frequency and Distribution of Chest Radiographic Findings in COVID-19 Positive Patients. Radiology. 2020;296:E72-E78. doi: 10.1148/ radiol.2020201160 15

17. Guan W, Ni Z, Hu Y, Liang W, Ou C, He J, et al. Clinical characteristics of coronavirus disease 2019 in China. N Engl J Med. 2020; 382:1708-1720. doi: 10.1056/NEJMoa2002032

18. Muurlink OT and Taylor-Robinson AW. COVID-19: Cultural Predictors of Gender Differences in Global Prevalence Patterns. Front. Public Health, 30th April 2020. doi: 10.3389/fpubh.2020.00174

19. Guan W, Liang W, Zhao Y, Liang H, Chen Z, Li Y, et al. Comorbidity and its impact on 1590 patients with COVID-19 in China: A Nationwide Analysis. Eur Respir J. 2020;55(5). doi: 10.1183/13993003.00547-2020

20. Jin J, Bai P, He W, Wu F, Liu X, Han D, et al. Gender Differences in Patients With COVID-19: Focus on Severity and Mortality. Front. Public Health. 2020;8:152 doi: 10.3389 /fpubh.2020.00152

\section{Authors Contribution:}

TN conceived, did manuscript writing, data collection, editing, review, final approval of manuscript and is responsible for integrity of the study.

NN did data collection, manuscript writing, statistical analysis and responsible and accountable of study.

SLK did data collection and compilation. 